\title{
A Preliminary Study of English Mobile Learning Model Based on Constructivism*
}

\author{
Jiaosheng Qiu \\ Taishan University, China
}

\begin{abstract}
This paper aims at exploring the model of English mobile learning system based on constructivism. Firstly, it defines the concepts of constructivism, constructivism learning theory, mobile learning and mobile learning theory. Then, it summarizes and analyses the relevant researches on mobile learning at home and abroad. Then it elaborates the purpose, significance and research value of the topic, respectively. The research hypothesis is put forward, and the English mobile learning model based on constructivist learning theory is preliminarily expounded. Finally, the research ideas, research methods, technical routes and implementation steps are explained.
\end{abstract}

Index Terms—English mobile learning, learning model, constructivism

\section{INTRODUCTION}

The Ten-Year Development Plan of Educational Informatization (2011-2020) issued by the Ministry of Education in 2012 indicates that higher education informatization is an effective way to promote higher education reform, innovation and quality improvement, as well as an innovative frontier in the development of educational informatization. It also proposes to promote the modernization of educational content, teaching means and methods by promoting the deep integration of information technology and education and teaching. No. 5. Mobile learning, with its advantages of mobility, wireless, portability and resource sharing, will not only fill the gap of traditional learning, but also become a new hotspot of educational informatization (Fan Wenxiang, etc., 2015). In view of this, this paper aims to carry out a comprehensive study of English mobile learning, striving to combine model research with practical research, not only to construct a new theoretical framework, but also to examine the learning indicators under the guidance of this framework, and to put forward suggestions for improvement, so as to realize the optimization of English mobile learning.

The English mobile learning model based on constructivist learning theory is adapted to the current trend of College English reform. With the development of practical teaching in the future, it will certainly provide some reference for college English teaching in the future.

\section{LITERATURE REVIEW}

\section{A. Constructivism}

Constructivism is a theory about knowledge and learning, which emphasizes learners' initiative. It holds that learning is a process in which learners generate meaning and construct understanding based on their original knowledge experience, which is often accomplished in the interaction of society and culture. The proposition of constructivism has a profound ideological origin, which is quite different from the traditional learning theory and teaching thought, and has important guiding value for teaching design. (Baidu Encyclopedia, 2019)

Constructivism, as a branch of cognitive theory, is the further development from behaviorism to cognitivism in learning theory. It is the latest teaching theory of western educational psychology (Fan Lin, Zhang Qiyun 2003), which is consistent with quality education. Constructivist learning theory advocates teacher-guided, student-centered learning, which consists of four elements: context, collaboration, conversation and meaning construction. Constructivism teaching mode emphasizes students as the center, regards students as the main body of cognition, and is the active constructor of knowledge meaning. Teachers only help and promote the construction of students'meaning (He Kekang, 1997). The curriculum design of the new teaching mode based on constructivism theory puts forward a more three-dimensional and comprehensive requirement for teachers to prepare lessons. They should prepare not only textbooks, but also students, materials and environment (Si Xianzhu, Zhao Haiyan, 2013).

\section{B. Constructivist Learning Theory}

Constructivism originates from the theory of children's cognitive development. Because individual's cognitive

\footnotetext{
* Fund projects: Shandong Social Sciences Planning Research Project “Analysis and Mechanism of College Students' English Mobile Learning Adaptation from the Perspective of Dynamic System Theory” (17CWZJ16), "A Study on the Development Model of College Freshmen's English Learning Adaptation from the Dynamic Perspective” (16CWZJ08); Shandong Education Science Planning Project "Application of Mobile Micro learning Based on Mobile Phone Terminal in College English Teaching" (BCGW2017011); Taishan University Teaching Reform Project "Research on the Reform and Practice of College English Teaching Guided by the Output-oriented Approach" (201846)
} 
development is closely related to learning process, constructivism can better explain the cognitive law of human learning process, that is, how learning occurs, how meaning is constructed, how concepts are formed, and what main factors should be included in the ideal learning environment. In a word, under the guidance of constructivism, a set of new and effective cognitive learning theories can be formed, and on this basis, an ideal constructivism learning environment can be realized.

The basic content of constructivist learning theory can be explained from two aspects: the meaning of learning (that is, what is learning) and the method of learning (that is, how to learn).

Constructivism advocates learner-centered learning under the guidance of teachers. That is to say, it emphasizes the learner's cognitive role and does not ignore the teacher's guiding role. Teachers are helpers and promoters of meaning construction, not imparters and inculcators of knowledge. Students are the subject of information processing and the active constructor of meaning, not the passive recipient of external stimuli and the object of inculcation. To become an active constructor of meaning, students are required to play a principal role in the process of learning from the following aspects: firstly, to construct the meaning of knowledge by exploring and discovering; secondly, to collect and analyze relevant information and materials on their own initiative in the process of meaning construction; thirdly, to put forward various hypotheses and try to verify them; thirdly, to construct the meaning of knowledge by exploring and discovering. We should try our best to connect the current learning content with what we already know, and give serious consideration to this connection.

Teachers are required to play a guiding role in the process of teaching in order to help students construct meanings: first, to stimulate students' interest in learning and help students form learning motivation; then, to help students construct the meaning of current knowledge by creating situations that meet the requirements of teaching content and prompting clues between new and old knowledge; finally, to help students construct the meaning of current knowledge. In order to make meaning construction more effective, teachers should organize collaborative learning (discussion and communication) under possible conditions, and guide the process of collaborative learning to the direction of meaning construction. The guiding methods include: putting forward appropriate questions to arouse students' thinking and discussion; trying to deepen students' understanding of what they have learned step by step in the discussion; inspiring and inducing students to discover rules themselves, correct and supplement wrong or one-sided understanding by themselves. (Baidu Encyclopedia, 2019)

Constructivism is the further development of behaviorism after it develops to cognitivism. After long-term theoretical exploration and teaching practice, a unique learning theory system has gradually been formed. Many viewpoints and propositions of constructivist learning theory are reasonable and can be used for reference in the practice of educational reform (Wen Pengnian, Jia Guoying, 2002). As the latest theory of educational psychology, constructivist teaching concept has a good reference for college English teaching and the cultivation of innovative talents in China. Today, with emphasis on improving students'comprehensive quality, using constructivist learning theory to guide English teaching has certain guiding significance for the cultivation of students' autonomous learning ability, divergent thinking ability and innovative ability (Fengyufang, 2006).

Constructivist learning theory has an intrinsic connection with the current English teaching reform. It puts forward a series of new ideas, which have profound implications for the reform of traditional teaching, the teaching reform of English subject and the innovative education in English teaching.

\section{Mobile Learning}

Mobile learning is an extension of digital learning based on mobile devices. It is a new field of e-learning. It is a situational learning method that learners use mobile terminals to provide wireless networks. It complements and complements other learning methods, thus improving learners' learning efficiency and optimizing learners' learning environment.

In summary, mobile learning is a new type of digital learning mode which combines the development of mobile technology and digital learning technology. The academia mainly defines mobile learning from three perspectives: technology-centered, cognitive-learning-centered and technology-learning-integrated. Based on different definitions, we believe that mobile learning is an extension of digital learning and a way for learners to access information, resources and carry out learning anytime and anywhere with the help of miniaturized mobile computing devices.

\section{Theoretical Basis of Mobile Learning}

\section{Activity Theory}

The philosophical basis of activity theory is the dialectical materialist philosophy of Marx and Engels. The basic content of activity theory research is the process of human activities, the two-way interaction between human and natural environment, social groups and natural environment, and the practice process and result of human individuals and groups. Human consciousness and activity are the unity of dialectics. That is to say, human psychological development and human external activities are dialectically unified.

The basic unit of analysis in activity theory is activity. The activity system consists of three core components (subject, object and community) and three secondary components (tools, rules and division of labor). Secondary components constitute the relationship between the core components. (Baidu Encyclopedia, 2019)

2. Informal Learning 
The so-called "informal learning" refers to the learning form that receives new knowledge at the time and place of informal learning such as work, life and social intercourse. It mainly refers to the learning behavior in the situations of doing, playing and traveling, such as salon, reading, gathering and playing ball. At present, the total amount of knowledge acquired by informal learning will exceed $75 \%$ of the total amount of knowledge acquired by people (Yu Shengquan, Mao Fang, 2005). Informal learning in life can be analyzed in the following ways: listing existing informal activities within the organization with partners; asking people how to exchange knowledge informally with partners in a formal way; supporting informal practice group activities; and trying to learn knowledge in dialogue or other activities (Wang Wei, 2011).

\section{E. A Review of the Research Status at Home and Abroad}

Mobile learning is a new learning mode with the increasing popularity of multimedia technology and Internet application. It not only emphasizes the learner's subjective status and initiative, but also helps learners construct meanings through various forms of interaction. In view of the important role of mobile learning for learners, the academic community has also discussed mobile learning of English. Domestic research on English mobile learning mainly focuses on the following four categories: the first is the theoretical model of English mobile learning, which involves the construction and exploration of mobile English teaching or learning mode. The second category is the research of mobile English learning technology, which mainly focuses on the design and development of mobile English learning system. The third category is the research on the construction of English mobile learning resources, including the design and application of mobile learning resource packages, and the exploration of the integration of information technology or assisted mobile digital learning resource system with English curriculum. The fourth category is the practical study of English mobile learning, which aims to focus on the application and Empirical Study of mobile learning in English language competence training, including the empirical study of English listening, speaking and writing teaching and the application of vocabulary learning. The fifth category is the current situation survey of English mobile learning, aiming at investigating and analyzing the current situation of college students' English mobile learning, putting forward improvement strategies to improve the efficiency of mobile learning, and providing reference for future research.

The classification of mobile learning in foreign countries is similar to that in domestic countries. It mainly involves the exploration of theoretical models or methods, the technical research of improving English vocabulary and overall language level, the practical research of improving learners' English listening and writing skills, and two or more skills. It also includes the exploration of the use of mobile learning strategies in English.

It can be seen that in recent years, researchers at home and abroad have focused on a single theoretical model, technology and design research, resource construction, strategy use or practical application of mobile learning. Multidimensional comprehensive research on English mobile learning needs to be carried out. Individual researchers (Chen Weichao, Liu Navy, 2009; Liu Yandong, 2012) attempted to study the instructional design of English Mobile Learning under the guidance of constructivist learning theory, but failed to construct a complete English mobile learning model, nor did they verify the learning effect, nor did they study the learners' autonomous learning ability and learning under the guidance of constructivist learning theory. Longitudinal investigation and inquiry were carried out on learning attitude and motivation. Different from the traditional teaching mode which focuses on teacher-centered knowledge imparting and learners' passive acceptance and mechanical memory learning, constructivist learning theory emphasizes learner-centered learning and advocates learners' autonomous learning and active construction of meaning under the guidance of teachers. Guided by constructivist learning theory is also the value of this study.

\section{The SignificANCE AND VAluE OF THE RESEARCH}

From the perspective of constructivist learning theory, this paper takes tests, questionnaires, interviews and classroom observations as the research methods, and takes English majors and non-English majors as the research objects, aiming at achieving the following objectives: Firstly, by exploring the conjunction between constructivist learning theory and English mobile learning, we construct an English mobile learning model based on constructivist learning theory. Then, based on the new model of construction, this paper makes a horizontal comparison and longitudinal tracking survey on learners'learning effect, autonomous learning ability and learning motivation, and explores the possible factors affecting the changes of learners' indicators, with a view to providing reference for future mobile English learning.

\section{A. Theoretical Significance and Value}

There is still a lack of English mobile learning model based on constructivist learning theory in China. This paper makes a systematic study of this issue, which is of great significance to reveal the essence of English mobile learning for learners.

This paper systematically examines the changes of learning effect, autonomous learning ability, learning motivation and other indicators under the new model by using the quantitative and qualitative research methods, and reveals the causes of affecting English mobile learning in an all-round way.

A cross-sectional comparison and a longitudinal follow-up study under the new model can better reveal the characteristics of learners'English mobile learning process. 


\section{B. Practical Significance and Value}

Under the guidance of constructivist learning theory, the practical study of English mobile learning model will help to test its theoretical characteristics and application value effectively, which is one of the important practical significance of this paper.

The study of English mobile learning model based on constructivist learning theory can provide a basis for deepening the reform of English teaching. The results can directly serve English mobile learning and help solve the problems existing in the process of English mobile learning.

Construct English mobile learning model based on constructivist learning theory, clarify the factors affecting English mobile learning, and provide reference for English teaching and learning.

\section{RESEARCH DESIGN}

\section{A. Research Objectives}

Based on constructivist learning theory, this paper explores how mobile technology-based learning occurs and produces meaning construction, so as to draw on the reasonable factors of Constructivism to carry out practical research on the construction of English mobile learning model.

To verify the support of constructivist learning theory for new learning methods and whether it can provide a theoretical framework for English mobile learning, so as to make the new learning model meet the requirements of student-centered mobile learning.

Focus on the combination of constructivism and mobile learning characteristics, and use empirical methods to connect teaching theory, learning methods and technical characteristics, so as to combine English mobile learning model with constructivism learning theory and put it into practice.

\section{B. Research Contents}

On the theoretical level, by sorting out and analyzing the relevant literature, we can grasp the concepts of constructivist learning theory, the history and current situation of English mobile learning at home and abroad comprehensively and correctly; by clarifying the literature, we can form a comparative analysis of the actual data, summarize and summarize the information data, and construct the English mobile learning model under the constructivist learning theory.

On the empirical level, this paper conducts an applied study of English mobile learning model based on constructivist learning theory. Specifically:

1) Build a mobile learning platform for Wechat and integrate English learning inside and outside the classroom. The learners make use of the personal chat, group chat and circle of friends in the form of text, voice and video to realize the interaction between teachers, students, teachers and students in English learning and English mobile learning platform.

2) Based on the constructivist learning theory, we attach importance to the interaction among teachers, learners and learning resources in the process of learning, strive to create a good learning environment, and create an interactive English mobile learning environment with the characteristics of associative thinking, self-consultation and mutual consultation. Combining theory with learning platform, the construction of new model is completed.

3) To investigate the learning effect under the guidance of the new learner model by combining the qualitative and directional methods, which mainly involves the change trends of learning achievement post-test, autonomous learning ability, learning attitude, learning motivation and so on, and then explore the causes of these changes.

4) Combining the materials collected from interviews and classroom observations, the new model is improved and perfected. According to the results of the study, this paper puts forward some useful suggestions for mobile English learning, and the revised model can be further put into practice.

\section{Research Hypothesis}

1) With constructivist learning theory as the theoretical framework, through the establishment of mobile English learning platform based on mobile phone Wechat and the analysis of interaction in and out of English classroom teaching, mobile English learning model under Constructivist Learning Theory can be used for English teaching and learning.

2) Compared with the traditional college English learning model, the English mobile learning model based on constructivist learning theory can effectively improve learners' English learning effectiveness, enhance their autonomous learning ability and motivation.

\section{Innovation Points}

1) Previous studies have paid more attention to individual aspects of English mobile learning. Individual mobile learning studies conducted under the guidance of constructivist learning theory are limited to the instructional design of computers and enterprise training, and do not involve the field of English mobile learning. This paper constructs an English mobile learning model based on constructivist learning theory for the first time.

2) An empirical study of English mobile learning model based on constructivist learning theory is carried out for the first time. By using the method of simultaneous multi-group and group tracking, we can not only compare the effect of 
English Mobile Learning under the new model, but also discover the development track of learners' language ability under the new model, so as to reveal the essence of learners' English mobile learning.

\section{E. Implementation Steps}

\section{Research ideas of this paper}

The first stage: preparation for the early stage and the beginning stage. This paper systematically collects and classifies the relevant literature at home and abroad, further defines the research technology route and periodic achievements, clarifies the constructivist learning theory at the theoretical level, defines the core concepts of mobile learning, and explores the research methods of mobile learning.

The second stage: the specific implementation stage of the project. An English mobile learning platform based on mobile Wechat is built, which is mainly composed of different interactive forms such as private chat, circle of friends, Wechat group and so on. Emphasis is laid on theoretical research in the early stage, and empirical research in the later stage. This paper expounds the constructivist learning theory and the research methods of English mobile learning from the theoretical level, and preliminarily constructs an English mobile learning model based on constructivist learning theory.

The third stage is to analyze the interaction between teachers and students, students and students, teachers and learning resources, and to improve the construction of English mobile learning model under the constructivist learning theory by using the mobile phone Wechat English learning platform.

The fourth stage: An experimental study on the application of English mobile learning model based on constructivist learning theory is conducted to test and evaluate the effectiveness of the model, whether it can promote interaction in English mobile learning, whether it can stimulate and maintain learners' interest in learning, whether it can improve learners' English level, and whether it can be recognized and favored by learners. On the empirical level, this paper evaluates the effectiveness of English mobile learning model based on constructivist learning theory, and conducts a horizontal comparison and longitudinal tracking study of English mobile learning by means of information technology such as mobile micro-messaging and virtual simulation technology. Based on the constructivist learning theory, this paper conducts a comparative and follow-up survey of learners' learning effectiveness, autonomous learning ability, learning attitude, learning motivation and various influencing factors through six months' and one and a half years' teaching practice, using language proficiency tests, questionnaires, interviews and classroom observation. According to the teaching feedback, we should further improve the English mobile learning model under the constructivist learning theory.

2. Research methods and technical routes

This paper investigates the effectiveness of the English mobile learning model based on constructivist learning theory by combining quantitative (test, questionnaire) and qualitative (interview, classroom observation). It is intended to take full-time English majors and non-English majors from several universities in Beijing (such as Beijing Foreign Studies University and Beijing Jiaotong University) as the research subjects, with English learners as the subjects. The changes of language proficiency test scores, autonomous learning ability and learning attitude are the specific indicators. Horizontal comparative study subjects can be divided into experimental group and control group. The experimental group adopted the brand-new English mobile learning model we constructed, while the control group used the traditional learning model to examine whether there were differences in many specific indicators between the two groups after a period of six months. The subjects of the longitudinal tracking study are mainly English majors. A one-and-a-half-year follow-up survey of English learning has been conducted to investigate the development of learners' English Mobile Learning under the new model. The questionnaire mainly includes the autonomous learning ability, learning attitude and learning effect of mobile Wechat. We will also design structured interviews to collect some of the participants' views on English mobile learning as a further verification and supplement to the quantitative results. In addition, through classroom observation and analysis of the advantages and disadvantages of English mobile learning, as well as the performance of the experimental subjects. SPSS 20.0 and NVivo 11 were used as analysis tools, t-test and structural equation model were used for statistical analysis of experimental quantitative data, and NVivo 11 was used for bottom-up grounded analysis of qualitative data.

\section{CONCLUSION}

Under the background of educational informationization, mobile learning is considered as one of the most important learning modes in the future. In College English teaching, mobile learning starts with teaching methods, teaching means, teaching technology and teaching methods, assists in solving the problems of insufficient English teaching hours, students' low interest in English and inefficient learning, and guides students to adopt correct learning methods to form good learning habits in the process of learning English, so as to improve the quality of English teaching in higher vocational colleges and truly realize them. The purpose of English education.

The English mobile learning model based on constructivist learning theory is adapted to the current trend of College English reform. With the development of practical teaching in the future, it will certainly provide some reference for college English teaching in the future. 


\section{REFERENCES}

[1] Baidu Encyclopedia. (2019). https://baike.baidu.com/item/constructivism/1428706?Fr=aladdin, (accessed 21/5/2019).

[2] Baidu Encyclopedia. (2019). https://baike.baidu.com/item/activity theory/2485429, (accessed 21/5/2019).

[3] Chen Weichao. (2009). Current Situation and Development Suggestions of Mobile Learning in China. China Electric Power Education, 07, 16-18.

[4] Fan Lin, Zhang Qiyun. (2003). The Combination of Constructivist Teaching Theory and English Teaching Reform. Foreign Language and Foreign Language Teaching, 04, 28-32.

[5] Fan Wenxiang, Ma Yan, Li Kai, Qiu Bingfa. (2015). Exploration of flipping classroom practice supported by Wechat in mobile learning environment. Open education research, 03, 90-97.

[6] Feng Yufang. (2006). Six Elements of Constructivist Learning Design Application in English Teaching. Foreign Language and Foreign Language Teaching, 06, 33-36.

[7] He Kekang. (1997). Teaching mode, teaching method and teaching design. Journal of Beijing Normal University (Social Science Edition), 05, 74-81.

[8] Liu Yandong. (2012). Research on Instructional Design of mobile learning based on constructivist learning theory. Journal of Hezhou University, 01,102-106.

[9] Si Xianzhu, Zhao Haiyan. (2013). College English Curriculum Design from the Perspective of Constructivism Teaching Mode. Foreign Language Audiovisual Teaching, 03, 70-74.

[10] Wang Wei. (2011). Research on Mobile Learning System Model of College English. Master Dissertation, Northeast Normal University.

[11] Wen Pengnian, Jia Guoying. (2002). Constructivist Theory and Teaching Reform - A Summary of Constructivist Learning Theory. Educational Theory and Practice, 05, 17-22.

[12] Yu Shengquan, Mao Fang. (2005). Informal Learning: A New Field of E-Learning Research and Practice. Research on Audiovisual Education, 10, 18-23.

Jiaosheng Qiu was born in Tengzhou, China in 1983. He received his master's degree in foreign linguistics and applied linguistics from Shandong Agricultural University, China in 2012.

$\mathrm{He}$ is currently a lecturer in the Department of College Foreign Languages Teaching, Taishan University, Tai'an, China. His research interests include Second Language Acquisition and College English Teaching. 